\title{
PELINDIAN LEBURAN PASIR ZIRKON KALIMANTAN MENGGUNAKAN AIR PANAS BENCH SCALE
}

\author{
Sajima, Triyono \\ Pusat Sains dan Teknologi Akselerator - BATAN \\ Jln. Babarsari, Kotak Pos 6101 ykbb, Yogyakarta 55281 \\ Telp (0274) 488435, Fax (0274)489762, \\ e-mail: sajima@batan.go.id
}

\begin{abstract}
ABSTRAK
PELINDIAN LEBURAN PASIR ZIRKON KALIMANTAN MENGGUNAKAN AIR PANAS BENCH SCALE. Telah dilakukan pengambilan silikat menggunakan cara pelindian air panas bench scale dengan bahan baku pasir zirkon Kalimantan. Perangkat ini terdiri atas bejana silinder gelas sebagai reaktor dengan kapasitas $800 \mathrm{~mL}$, dilengkapi pemanas dan pengaduk. Mula-mula dimasukkan pelarut (air bebas mineral) sebanyak $600 \mathrm{~mL}$ ke dalam reaktor, kemudian dipanaskan sambil diaduk. Setelah temperatur tercapai, umpan dimasukkan. Temperatur proses dan kecepatan pengadukan dikendalikan tetap. Apabila kondisi operasi tercapai, proses pelindian dihentikan, kemudian dipisahkan padatan dari filtrat. Silikat dalam padatan dan filtrat dianalisis menggunakan AAS. Penelitian ini mempelajari pengaruh temperatur, waktu dan kecepatan pengadukan pelindian. Hasil penelitian menunjukkan bahwa temperatur pelindian optimum pada $80^{\circ} \mathrm{C}$ kecepatan pengadukan $200 \mathrm{rpm}$ dan waktu pelindian 60 menit. Pada kondisi tersebut silikat terambil $84,60 \%$.
\end{abstract}

Kata kunci: pelindian, konsentrat zirkon, air panas bench scale.

\begin{abstract}
KALIMANTAN ZIRCON SAND LEACHING BY HOT WATER BENCH SCALE METHOD. Silicate extraction using hot water bench scale leaching method was done using Kalimantan zircon sand as raw materials. Hot water bench scale equipment consists of a $800 \mathrm{~mL}$ cyllindrical glass vessel as a reactor embedded with heater and stirrer.Initially, about $600 \mathrm{~mL}$ solvent (demineral water) was poured into reactor. Then, the solvent was stirred and heated. The raw material was introduced into reactor after solvent was in desired temperature. During this process, temperature and stirring speed were controlled.In the final process, the solids were separated from its filtrate which is further analyzed using Atomic Absorption Spectroscopy (AAS). The goal of this research was to study the effect of temperature, reaction time, and stirring speed on leaching process. According to the result, process with temperature of $80^{\circ} \mathrm{C}$; stirring speed of 200rpm: and 60 minute reaction time showed the optimum leached sillicate product which is $84,60 \%$.
\end{abstract}

Key words: leaching, zircon concentrate, hot water bench scale

\section{PENDAHULUAN}

Salah satu implementasi peningkatan kesejahteraan masyarakat yaitu dengan disahkan- nya Undang undang Minerba No 5 tahun 2012 tentang pertambangan mineral dan batubara melalui peraturan menteri ESDM nomor 5 Tahun 2017 menjelaskan bahwa adanya larangan penjualan bijih (raw material atau ore) mineral ke luar negeri ${ }^{[1]}$.
Mineral zirkon $\left(\mathrm{ZrSiO}_{4}\right)$ termasuk cadangan bijih kadar rendah (low grade/lateric ores) dan sebagai mineral ikutan banyak tersebar di sepanjang tin belt selat Malaka dan sebagai tailing penambangan emas di Pulau Kalimantan seperti disajikan Tabel $1^{[2]}$. Pasir zirkon apabila diolah lebih lanjut, akan memiliki peran yang sangat strategis terkait dengan industri nuklir maupun industri aplikatif lainnya ${ }^{[3]}$. 
Tabel. 1. Deposit mineral zircon di daerah aliran sungai (DAS) Kalimantan Tengah

\begin{tabular}{lrrr}
\hline \multicolumn{1}{c}{ Lokasi } & \multicolumn{1}{c}{$\begin{array}{c}\text { Volume } \\
\text { Endapan } \\
\left(\mathrm{m}^{3}\right)\end{array}$} & $\begin{array}{c}\text { Jumlah } \\
\text { Konsen- } \\
\text { trat (ton) }\end{array}$ & $\begin{array}{r}\text { Kandungan } \\
\mathrm{ZrSiO}_{4}(\text { ton })\end{array}$ \\
\hline DAS Sekonyer & 88.500 .000 & 513.300 & 384.975 \\
DAS Seruyan & 11.820 .000 & 68.556 & 44.561 \\
DAS Mentaya & 102.140 .000 & 592.412 & 385.068 \\
DAS Katingan & 235.400 .000 & 1.318 .240 & 777.767 \\
DAS Rungan & 21.900 .000 & 122.640 & 74.810 \\
DAS Muroi & 22.560 .000 & 126.336 & 63.168 \\
DAS Kapuas & 35.800 .000 & 200.480 & 100.240 \\
Lain lain & 103.292 .000 & 516.460 & 258.230 \\
Total & $\mathbf{1 . 1 7 4 . 6 6 3 . 0 0 0}$ & $\mathbf{6 . 5 5 6 . 6 3 0}$ & $\mathbf{2 . 6 1 5 . 5 0 9}$ \\
\hline
\end{tabular}

Pada industri nuklir, bahan ini dapat diolah menjadi zirkonia atau sebagai bahan keramik maju karena memiliki kekuatan yang tinggi dan titik lebur yang sangat tinggi $\left(2700{ }^{\circ} \mathrm{C}\right)$. Selain itu, bahan ini juga memiliki konduktivitas ion oksigen, konduktivitas termal yang rendah, fleksibilitas yang tinggi, dan ketahanan terhadap korosi sehingga dapat diaplikasikan sebagai bahan pembuatan sensor oksigen. Sensor oksigen adalah perangkat yang dapat memantau konsentrasi oksigen pada sistem nuklir berpendingin lead alloy seperti pada LFR (Lead alloy-cooled Fast Reactor) maupun target spalasi pada ADS

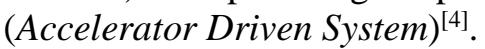

Pengolahan pasir zirkon diawali dari proses fisis dilanjutkan pemurnian secara kimiawi. Perangkat proses yang digunakan dalam pengolahan secara fisis antara lain meja goyang, magnetik separator dan high tension separator. Pemisahan menggunakan meja goyang adalah proses pemisahan berdasarkan perbedaan massa jenis antar mineral, sedangkan proses pemisahan menggunakan magnetik separator adalah proses pemisahan mineral berdasarkan perbedaan sifat kemagnetan mineral. High tension separator merupakan perangkat pemisahan mineral berdasarkan perbedaan sifat kelistrikan mineral ${ }^{[5]}$.

Tahap pertama pada pemurnian dalam olah mineral zirkon adalah peleburan pasir zirkon dan pelindian menggunakan air ${ }^{[3]}$. Reaksi yang terjadi pada proses peleburan diduga sebagai berikut ${ }^{[6]}$ :

$$
\begin{aligned}
& \mathrm{ZrSiO}_{4}+2 \mathrm{NaOH} \rightarrow \mathrm{Na}_{2} \mathrm{ZrSiO}_{5}+\mathrm{H}_{2} \mathrm{O} \\
& \mathrm{ZrSiO}_{4}+4 \mathrm{NaOH} \rightarrow \mathrm{Na}_{2} \mathrm{ZrO}_{3}+\mathrm{Na}_{2} \mathrm{SiO}_{3}+2 \mathrm{H}_{2} \mathrm{O} \\
& \mathrm{ZrSiO}_{4}+6 \mathrm{NaOH} \rightarrow \mathrm{Na}_{2} \mathrm{ZrO}_{3}+\mathrm{Na}_{4} \mathrm{SiO}_{4}+3 \mathrm{H}_{2} \mathrm{O}
\end{aligned}
$$

Pelindian atau leaching adalah proses pengambilan solut dari padatan dengan pelarut tertentu. Proses leaching terjadi dalam dua tahap, yakni kontak antara padatan dengan pelarut sehingga terjadi perpindahan massa dari padatan ke larutan dan pemisahan padatan dan larutan setelah proses selesai ${ }^{[7]}$. Mekanisme reaksi yang terjadi pada proses pelindian dengan air sebagai berikut ${ }^{[8]}$ :

$\left(\mathrm{Na}_{2} \mathrm{ZrO}_{3}+\mathrm{Na}_{2} \mathrm{SiO}_{3}\right)+8 \mathrm{H}_{2} \mathrm{O} \rightarrow \mathrm{Na}_{2} \mathrm{ZrO}_{3}+\mathrm{Na}_{2} \mathrm{SiO}_{3} .8 \mathrm{H}_{2} \mathrm{O}$

Faktor-faktor yang mempengaruhi proses pelindian antara lain: kecepatan pengadukan temperatur dan waktu pelindian ${ }^{[9]}$. Laju pelarutan sangat tergantung pada kecepatan putaran pengadukan. Kecepatan pengadukan biasanya dinyatakan dengan gradien kecepatan. Gradien kecepatan merupakan fungsi dari tenaga yang diberikan $(\mathrm{P})^{[9]}$.

$$
G=\sqrt{\frac{P}{\mu V}}
$$

dalam hal ini:

$\mathrm{G}=$ Gradien kecepatan

$\mathrm{P}=$ tenaga yang diberikan ke target (N.m/detik)

$\mathrm{V}=$ Volume target yang diaduk $\left(\mathrm{m}^{3}\right)$

$\mu$ =viskositas absolut target (N.detik $\left./ \mathrm{m}^{2}\right)$.

Menurut Habashi, temperatur berpengaruh meningkatkan konstanta reaksi pelarutan dan konstanta reaksi difusi pada reaksi heterogen ${ }^{[10]}$. Hal ini didukung dengan kenyataan bahwa pada konsentrasi reaktan yang rendah, reaksi pelarutan akan memiliki energi aktivasi yang rendah, sedangkan pada konsentrasi yang tinggi maka proses pelarutan akan memiliki energi aktivasi yang tinggi pula. Persamaan laju difusi memiliki bentuk yang analog dengan persamaan laju reaksi kimia. Tetapan laju reaksi kimia tergantung secara eksponensial pada temperatur, sesuai persamaan Arhennius ${ }^{[10]}$.

$$
k=A \cdot \operatorname{Exp} .(-E / R T)
$$

dengan :

$\mathrm{k}=$ konstanta laju reaksi

$\mathrm{A}=$ konstanta integrasi atau faktor frekuensi

$\mathrm{E}=$ Energi aktivasi ( $\mathrm{kal} / \mathrm{mol})$

$\mathrm{R}=$ tetapan gas ideal $(1,987 \mathrm{kal} / \mathrm{mol} . \mathrm{K})$

$\mathrm{T}=$ Temperatur mutlak $(\mathrm{K})$

Konfirmasi kandungan silikat (Si) pada sampel hasil maupun umpan dilakukan dengan metode Atomic Absobstion Spectrofotometri (AAS), karena $\mathrm{Si}$ merupakan unsur yang 
mudah membentuk oksida dan sulit terurai. Metode ini merupakan cara analisis yang berdasarkan pada penyerapan energi radiasi oleh atom-atom yang berada pada tingkat dasar (ground state) ${ }^{[11]}$. Adanya penyerapan tersebut menyebabkan elektron mengalami eksitasi ke level energi yang lebih tinggi. Keadaan tersebut tidak stabil, sehingga elektron akan kembali ke posisi ground state dengan memancarkan energi yang berupa radiasi. Radiasi yang dipancarkan bersifat khas karena mempunyai panjang gelombang yang khas untuk setiap atom bebas. Hubungan kuantitatif antara intensitas radiasi yang diserap dan konsentrasi unsur dalam larutan menjadi dasar penggunaan AAS untuk analisis unsur logam. Sehingga berlaku Hukum Lambert-Beer yang dirumuskan dengan persamaan $(7,8)$ :

$$
\begin{aligned}
& A_{x}=a \cdot C_{k} \\
& A_{T}=a\left(C_{s}+C_{x}\right)
\end{aligned}
$$

dengan:

$\mathrm{a}=$ koefisien serapan

$\mathrm{C}_{\mathrm{x}}=$ konsentrasi zat sampel

$\mathrm{C}_{\mathrm{s}}=$ konsentrasi zat standar yang ditambahkan ke larutan sampel

$\mathrm{A}_{\mathrm{x}}=$ absorbansi zat sampel (tanpa penambahan zat standar)

$\mathrm{A}_{\mathrm{T}}=$ absorbansi zat sampel + zat standar

Jika kedua rumus digabung maka akan diperoleh

$$
\mathrm{C}_{\mathrm{x}}=\mathrm{C}_{\mathrm{s}}+\left\{\mathrm{A}_{\mathrm{x}} /\left(\mathrm{A}_{\mathrm{T}}-\mathrm{A}_{\mathrm{x}}\right)\right\}
$$

Konsentrasi zat dalam sampel $\left(\mathrm{C}_{\mathrm{x}}\right)$ dapat dihitung dengan mengukur $A_{x}$ dan $A_{T}$ secara spektrometri. Jika dibuat suatu seri penambahan zat standar dapat pula dibuat grafik antara $\mathrm{A}_{\mathrm{T}}$ lawan $\mathrm{C}_{\mathrm{S}}$ garis lurus yang diperoleh dari ekstrapolasi ke $\mathrm{A}_{\mathrm{T}}=0$, sehingga diperoleh:

$C_{x}=C_{s} \times\left\{A_{x} /\left(0-A_{x}\right)\right\} ; C_{x}=C_{s} \times\left(A_{x} /-A_{x}\right)$
$C_{x}=C_{s} \times(-1)$ atau $C_{x}=-C_{s}$

Cara menghitung keberhasilan proses diguna kan persamaan $\operatorname{sbb}^{[5]}$ :

$$
R=\frac{X-Y}{X} \times 100 \%
$$

dengan:

$\mathrm{R}=$ silikat terambil

$\mathrm{X}=$ Si dalam umpan

$\mathrm{Y}=\mathrm{Si}$ dalam $\mathrm{Na}_{2} \mathrm{ZrO}_{3}$
Dwiretnani, dkk telah melakukan pengambil an silikat dengan cara pelindian menggunakan air pada kondisi temperatur kamar \% dalam skala laboratorium. ${ }^{[8]}$. Pada penelitian tersebut silikat terambil sebesar $65 \%$ begitu juga Reginaldo $\mathrm{dkk}^{[12]}$, berhasil mengambil silikat sebesar $80 \%$ pada temperatur $90{ }^{\circ} \mathrm{C}^{[12]}$. Sedangkan penelitian ini, pelindian dilakukan menggunakan air panas bench scale dengan kapasitas $800 \mathrm{~mL}$.

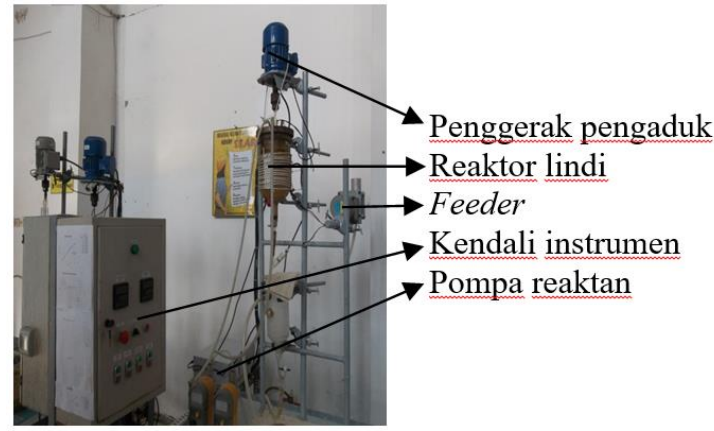

Gambar. 1. Reaktor pelindian menggunakan air panas bench scale

\section{METODE}

\section{Bahan yang digunakan}

Umpan (hasil proses peburan konsentrat zirkon dengan pereaksi $\mathrm{NaOH}$ teknis pada temperatur $800{ }^{\circ} \mathrm{C}$ selama 120 menit). Air bebas mineral digunakan untuk pelarut proses pelindian.

\section{Alat yang digunakan}

Timbangan digunakan untuk menimbang bahan. Satu perangkat reaktor pelindian yang dilengkapi dengan mantel pemanas, media pemanas dan pengaduk dengan sistem kendali. Pompa digunakan untuk mengalirkan pelarut (air bebas mineral). Penyaring vakum. Satu unit Spektrofotometer serapan atom digunakan untuk analisis unsur silaka ( $\mathrm{Si})$.

\section{Cara Kerja}

Pelarut (air bebas mineral) sebanyak $600 \mathrm{ml}$ dimasukkan ke dalam reaktor pelindian sambil diaduk. Media pemanas (minyak goreng) dimasukkan ke dalam bejana pemanas hingga batas yang telah ditentukan. Media pemanas dinaikkan temperaturnya hingga indikator mencapai temperatur yang telah ditentukan dengan cara menambahkan 
tegangan pada potensio pemanas. Setelah temperatur tercapai, umpan sebanyak 20 gram dimasukkan ke dalam reaktor pelindian melalui lubang feeder secara manual. Temperatur, waktu dan kecepatan pengadukan proses pelindian dipertahankan tetap (stabil). Apabila kondisi proses pelindian tercapai, perangkat proses dimatikan dan dibiarkan dingin. Hasil proses pelindian ditampung dan dibiarkan (dienapkan) selama \pm 24 jam kemudian dipisahkan menggunakan metode vakum. Kandungan silikat ( $\mathrm{Si}$ ) dalam filtrat maupun dalam padatan (natrium zirkonat) dianalisis menggunakan metode Atomic Absobstion Spectrofotometri (AAS). Penelitian dilakukan dengan variasi temperatur $\left(30,40,50,60,70\right.$ dan $\left.90{ }^{\circ} \mathrm{C}\right)$, waktu (10, 20, 30, 40, 50, 60, 70, 90 dan 100 menit) dan kecepatan pengadukan $(40,60,80,100,120$, 140, 160, 180 dan $240 \mathrm{rpm})$.

\section{HASIL DAN PEMBAHASAN}

Tahap awal dalam pemurnian pada pengolahan mineral zirkon dengan metode Kroll adalah proses peleburan dilanjutkan pelindian menggunakan air. Hasil proses (leburan) diharapkan berisi natrium zirkonat $\left(\mathrm{Na}_{2} \mathrm{ZrO}_{3}\right)$ dan natrium silikat $\left(\mathrm{Na}_{2} \mathrm{SiO}_{3}\right)$. Senyawa natrium silikat $\left(\mathrm{Na}_{2} \mathrm{SiO}_{3}\right)$ bersifat mudah larut dalam air, silikat mengalami difusi ke permukaan sehingga akan larut dalam air. Natrium zirkonat $\left(\mathrm{Na}_{2} \mathrm{ZrO}_{3}\right)$ tidak larut dalam air. Hasil percobaan pengaruh temperatur pelindihan terhadap $\mathrm{Si}$ terambil disajikan pada Gambar 2.

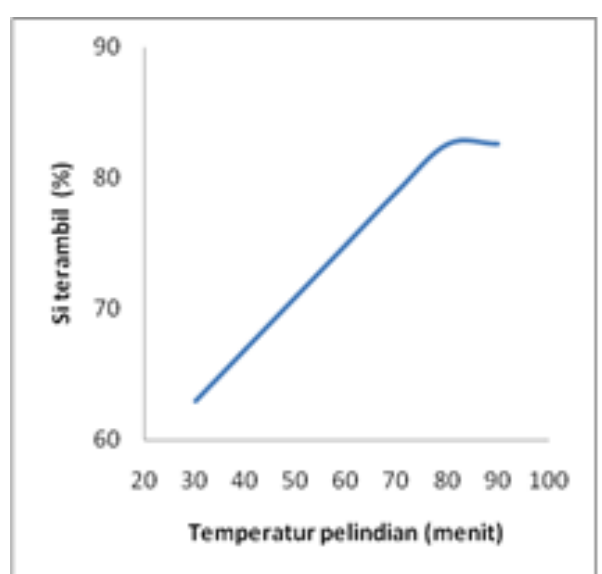

Gambar. 2. Pengaruh temperatur pelindian terhadap silikat terambil pada kecepatan pengadukan 200 rpm selama 80 menit.
Gambar 2. membuktikan bahwa temperatur pelindian sangat mempengaruhi jumlah silikat terikat dalam filtrat. Ketika proses pelindian dilakukan dengan menaikkan temperatur dari $30^{\circ} \mathrm{C}$ hingga $80^{\circ} \mathrm{C}$, jumlah silikat terambil mengalami kenaikkan secara signifikan $(63,00 \%$ menjadi 82,60\%). Hal ini sesuai dengan persamaan Arhennius, bahwa semakin tinggi temperatur menyebabkan energi aktifasi yang dimiliki zat penyusun bahan menjadi semakin besar pula, sehingga memacu gerakan zat lebih besar dan menimbulkan tumbukan antar molekul semakin intens akibatnya reaksi berjalan lebih sempurna. Namun, ketika temperatur proses dinaikkan lagi menjadi $90{ }^{\circ} \mathrm{C}$, diperoleh gambar dengan garis mendatar bahkan menjurus turun. Hal ini terjadi karena silikat dalam bentuk $\mathrm{Na}_{2} \mathrm{SiO}_{3}$ yang sudah larut dalam air berubah menjadi $\mathrm{SiO}_{2}$ bebas dan bercampur kembali dalam natrium zirkonat. Kondisi proses ini menunjukkan bahwa proses pelindihan terbaik pada temperatur $80^{\circ} \mathrm{C}$ dan silikat terambil sebanyak $82,60 \%$.

Hasil percobaan pengaruh waktu pelindian terhadap silikat terambil disajikan pada Gambar 3.

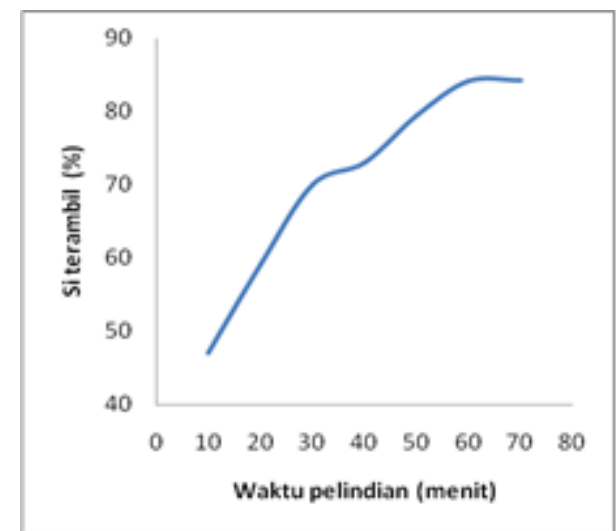

Gambar. 3. Pengaruh waktu pelindian terhadap silikat terambil pada kecepatan pengadukan $200 \mathrm{rpm}$ dan temperatur $80^{\circ} \mathrm{C}$.

Gambar 3 menunjukkan, apabila waktu proses pelindian dinaikkan dari 20 menit hingga 60 menit akan diperoleh garis mengarah ke atas. Hal ini menunjukkan bahwa jumlah silikat yang terambil mengalami kenaikan secara tajam $(47,00 \%$ menjadi $84,60 \%)$. Peristiwa ini membuktikan bahwa semakin lama waktu pelindian, menyebab kan kontak antar materi semakin tercukupi sehingga reaksi menjadi lebih sempurna. Namun ketika waktu pelindian diperpanjang hingga 80 menit, 
jumlah silikat terambil tidak mengalami penambahan yang berarti. Hal ini menunjukkan bahwa waktu peleburan optimum selama 60 menit dan silikat terambil $84,60 \%$.

Hasil percobaan pengaruh kecepatan pengadukan terhadap silikat terambil disajikan pada Gambar 4.

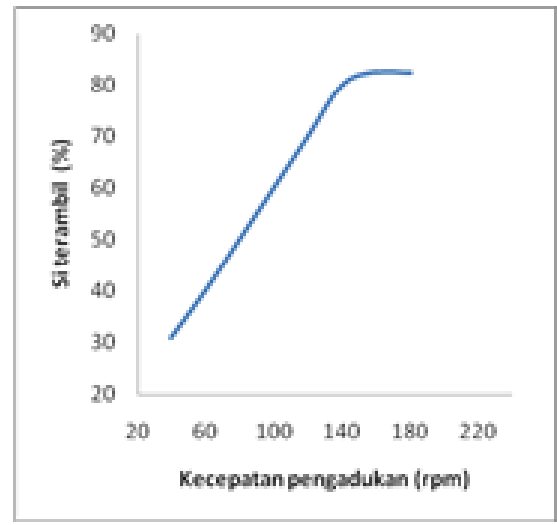

Gambar. 4. Pengaruh kecepatan pengadukan terhadap silikat terambil pada temperatur $80^{\circ} \mathrm{C}$ selama 60 menit.

Pada Gambar 4. tampak bahwa semakin cepat pengadukan (40 rpm menjadi $200 \mathrm{rpm}$ ) silikat terikat akan masuk ke dalam filtrat naik sangat signifikan $(31,00 \%$ menjadi 84,60 $\%$ ). Hal ini membuktikan bahwa tenaga merupakan fungsi Gradien kecepatan. Semakin cepat pengadukan menyebabkan tenaga yang dimiliki zat penyusun bahan menjadi semakin besar, sehingga menambah kekuatan gerak zat penyusun bahan, akibatnya reaksi berjalan lebih sempurna. Namun, ketika proses pengadukan dinaikkan terus menjadi $240 \mathrm{rpm}$, diperoleh gambar grafik dengan bentuk garis mendatar. Kondisi proses ini menunjukkan bahwa proses pelindian terbaik pada kecepatan pengadukan $200 \mathrm{rpm}$ dan silikat terambil sebanyak $84,60 \%$.

\section{KESIMPULAN}

Pelindian menggunakan air panas adalah metode pengambilan pengotor silikat. Temperatur, waktu dan kecepatan pengadukan sangat berpengaruh dalam proses pelindi an. Hasil percobaan menunjukkan bahwa kondisi proses pelindian optimum pada temperatur $80{ }^{\circ} \mathrm{C}$, kecepatan putar pengaduk 200 rpm selama 60 menit. Pada kondisi proses tersebut pengotor silikat terambil sebanyak $84,60 \%$.

\section{UCAPAN TERIMAKASIH}

Kami mengucapkan terimakasih kepada Ir. Moch. Setyadji, MT selaku kepala Bidang Teknologi Proses Pusat Sains teknologi Akselerator Badan Tenaga Nuklir Nasional Yogyakarta yang telah membantu baik dalam bentuk fasilitas, dana maupun peralatan bagi keberhasilan dan kelancaran kegiatan penelitian ini.

\section{DAFTAR PUSTAKA}

1. Peraturan Menteri ESDM No. 5 Tahun 2017 tentang Peningkatan Nilai Tambah Mineral melalui Kegiatan Pengolahan dan Pemurnian., 2017.

2. Zulfikar, Herry R.E, "Endapan Zirkon Di Daerah Pangkalan Batu, Kecamatan Kendawangan, Ketapang, Kalbar", Proceeding Pemaparan Hasil Kegiatan Lapangan dan Non Lapangan, Pusat Sumber Daya Geologi, 2008.

3. Routray, S., Padhi, L.N., Bera, T., "Recovery of Zirkons of South Eastern Coast of India Their Potential as Refractories and Ceramics", International Journal of Mechanical Engineering and Technology, Vol 5, Issue 5, pp 73-82, 2014.

4. Gessi., "Materials for Heavy Liquid Metal Cooled", workshop (21 - 23) May 2007.

5. Lubbe S, Munsami R., Fourie, D., 2012. "Beneficiation of Zircon Sand in South Africa", The Journal of The Southern African Institute of Mining and Metallurgy 7A, 583-588, July, 583 - 588, 2012.

6. Jingchong Liuc, Jing Song, Tao Qi, Changqiao Zhang, Jingkui Qu., "Controlling the Formation of $\mathrm{Na}_{2} \mathrm{ZrSiO}_{5}$ in Alkali Fusion Process for Zirconium Oxychloride Production", Journal Advanced Powder Technology (Elsevier) National Engineering Laboratory for Hydrometallurgical Cleaner Production Technology, Beijing 100190, China 29 August 2015

7. Ran Liu, Jing Kui Qu, Jing Song, Tao Qi, Ailing Du, "Analysis of Water Leaching and Transition in Zirconium Oxychloride Octahydrate Production", 2013.

8. Dwiretnani., "Pengambilan Silikat dari Hasil peleburan Pasir Zirkon dengan Pelindian Memakai Air", Prosiding Pertemuan dan Presentasi Ilmiah Bahan 
Murni dan Instrumentasi Nuklir, 22-25 . 1985, hal 689-699.

9. Moch Rosidi., "Pengadukan dalam Proses Koagulasi - Flokulasi, Chemistry Environment", 8 Juni 2015.

10 Habashi F, Textbook Metallurgy., 31 December 1999.

11. Wahyu Prasetyo Utomo., "Atomic Absobstion Spectrofotometri (AAS)", 15 November 2011.

12. Regigaldo, Achiles Junguera Bourdot Dutra, Julio Carlos Afonso., "Alkali Fusion Followed By Two Step Leaching Of A Brazillian Zircon Concentrate", Journal Hydrometallurgy, Volume 117, April 2012, Hal $93-100$. 